\title{
Oxidative coupling of methane using microwave dielectric heating
}

\author{
Xunli Zhang*, Colleen S.-M. Lee, D. Michael P. Mingos ${ }^{1}$, David O. Hayward \\ Department of Chemistry, Imperial College of Science, Technology and Medicine, South Kensington, London SW7 2AY, UK
}

Received 3 January 2003; received in revised form 26 February 2003; accepted 26 February 2003

\begin{abstract}
Microwave heating was applied in the oxidative coupling of methane to higher hydrocarbons over alumina supported $\mathrm{La}_{2} \mathrm{O}_{3} / \mathrm{CeO}_{2}$ catalysts. It was found that microwave heating had a dramatic effect on the reaction when methane was converted into $\mathrm{C}_{2}$ hydrocarbons in the absence of oxygen, with products produced at measured temperatures about $250^{\circ} \mathrm{C}$ lower than those observed with conventional heating. It was shown that the reaction in the absence of oxygen occurred primarily in the gas phase and it was the localised heating of the methane that was responsible for the increased reaction rate. However, it was observed that microwave heating did not produce significant "special microwave effects" which affected the product species formed when the oxidative coupling reaction occurred in the presence of oxygen.
\end{abstract}

(c) 2003 Elsevier Science B.V. All rights reserved.

Keywords: Microwave dielectric heating; Oxidative coupling of methane; Alumina supported $\mathrm{La}_{2} \mathrm{O}_{3} / \mathrm{CeO}_{2}$ catalyst

\section{Introduction}

The conversion of natural gas, of which methane is the major constituent, into value-added chemicals has received great attention in the last 20 years. Although the majority of the work studied has been focused on converting methane into synthesis gas [1-3], which can then be converted to higher hydrocarbons through the Fischer-Tropsch chemistry [4], some other work has shown the alternative route to convert methane directly into higher hydrocarbons by oxidative coupling [5-9]. In the oxidative coupling process, methane and oxygen are fed over a metal or metal oxide catalyst

\footnotetext{
* Corresponding author. Present address: Department of Chemistry, The University of Hull, Hull HU6 7RX, UK.

Tel.: +44-1482-382067; fax: +44-1482-382061.

E-mail address: x.zhang@hull.ac.uk (X. Zhang).

${ }^{1}$ Present address: St. Edmund Hall, The University of Oxford, Oxford OX1 4AR, UK.
}

at moderate temperatures $\left(500-800^{\circ} \mathrm{C}\right)$ to produce mainly ethane and ethylene. The early major study of oxidative coupling was done by Keller and Bhasin [5] in 1982 with numerous metals examined as possible catalysts. Since then, considerable work on oxidative coupling has focussed particularly on rare-earth metal oxides [6-9].

The application of microwave heating in heterogeneous catalytic reactions has been investigated since the late 1980s [10,11]. Studies comparing conventional heating and microwave radiation in the oxidative coupling of methane have been carried out by Bond et al. [12] using a number of basic oxides. The results from all of the catalysts tested confirm that microwave applied to the reaction results in $\mathrm{C}_{2}$ formation being attained at much lower temperatures with increased selectivity. This significant reduction in reaction temperature exceeds all attempts that have been made so far to improve catalyst activity when conventional 
heating is employed. Additionally, it has been found that microwave radiation resulted in an increased ratio of ethylene to ethane, which is desirable, and also an increased selectivity of $\mathrm{CO}$ at the expense of $\mathrm{CO}_{2}$. Roussy et al. [13] have also revealed an enhancement in higher hydrocarbons selectivity in oxidative coupling of methane over microwave-irradiated catalysts. Wan et al. [14] used pulsed-microwave radiation to study the reaction of methane in the absence of oxygen. The reaction has been performed over a series of nickel catalysts, and the products produced appeared to be a function of both the catalyst used and the power and frequency of the microwave pulses. In a study conducted by Chen et al. [15] on the microwave effects on the oxidative coupling of methane over rare-earth oxide catalysts, a change in both the product selectivity and the product species formed was also shown when compared to the conventionally heated reaction.

Although many processes have been developed for the conversion of methane to higher hydrocarbons, it is not yet clear how microwave pulses or continuous microwave heating induces oxidative coupling. The aim of this work has been to investigate the effect of microwave dielectric heating on the oxidative coupling of methane over supported rare-earth metal oxides, with particular attention paid to product species and product selectivities. The degree of oxidative coupling of methane occurring in the absence of metal oxide catalyst (using conventional heating) has also been studied. In addition, experiments have been carried out on the pyrolysis of methane, using both conventional and microwave heating in order to compare the mechanisms operating with and without oxygen present.

\section{Experimental}

\subsection{Materials}

Methane (purity 99.0\%) and oxygen (purity 99.6\%) were purchased from Aldrich. Argon (purified) was supplied by BOC Gas. Activated aluminium oxide $\left(99 \% \mathrm{Al}_{2} \mathrm{O}_{3}\right)$ was purchased from Alfa, Johnson Matthey $\mathrm{Plc}$ in white powder pellets with a surface area of $90 \mathrm{~m}^{2} \mathrm{~g}^{-1}$. Lanthanum nitrate hexahydrate $\left[\mathrm{La}\left(\mathrm{NO}_{3}\right)_{3} \cdot 6 \mathrm{H}_{2} \mathrm{O}\right]$ (purity $99.999 \%$ ) and cerium(III) nitrate hexahydrate $\left[\mathrm{Ce}\left(\mathrm{NO}_{3}\right)_{3} \cdot 6 \mathrm{H}_{2} \mathrm{O}\right]$ (purity 99.99\%) were also purchased from Aldrich.

\subsection{Catalyst preparation}

The catalyst used in this study was prepared by a two-step wet co-impregnation technique. In the first stage, an appropriate amount of lanthanum salt $\left[\mathrm{La}\left(\mathrm{NO}_{3}\right)_{3} \cdot 6 \mathrm{H}_{2} \mathrm{O}\right]$ solution, which was calculated to produce $10 \mathrm{wt} . \%$ of $\mathrm{La}_{2} \mathrm{O}_{3}$ loading on the support, was added to the ground alumina $(1 \mathrm{~g}$, powder size: $157-178 \mu \mathrm{m})$. The impregnated alumina was then dried in a tubular furnace at atmospheric pressure, by gradually increasing the temperature from 50 to $105^{\circ} \mathrm{C}$ over a period of $3 \mathrm{~h}$. This was followed by an isothermal heating period of $18 \mathrm{~h}$ at $105^{\circ} \mathrm{C}$. Once dried, the sample was calcined in a flow of air at $500{ }^{\circ} \mathrm{C}$ for a period of $2 \mathrm{~h}$. In the second stage, ceria was impregnated onto the supported sample obtained from the first impregnation with the appropriate amount of cerium salt $\left[\mathrm{Ce}\left(\mathrm{NO}_{3}\right)_{3} \cdot 6 \mathrm{H}_{2} \mathrm{O}\right]$ solution in the same procedure with the first step. After the two steps the alumina supported $10 \% \mathrm{La}_{2} \mathrm{O}_{3} / 20 \% \mathrm{CeO}_{2}$ catalyst was obtained.

\subsection{Characterization of catalyst}

The catalysts used in this study were characterised by using a combination of several analytical methods. The surface area was measured, before and after reaction, by the BET method using a Micromeritics ASAP-2000 analyzer. The composition of the catalysts before and after reaction was determined by X-ray powder diffraction using a PW1710 X-ray diffractometer (Phillips Electronic Instruments) with $\mathrm{Cu} \mathrm{K \alpha}$ radiation.

\subsection{Experimental procedures}

All reactions were carried out in a laboratory-scale, continuous-flow reaction system with a tubular packed-bed quartz reactor $(10 \mathrm{~mm}$ i.d.), which could be placed either in a cylindrical microwave cavity or in a conventional furnace [16,17]. A directional coupler was inserted into the microwave guide system so that the amount of microwave power reflected from the cavity could be measured. This was minimised by tuning the cavity with two adjustable stubs. The temperature of the catalyst was measured with an Accufiber optical fibre thermometer (Model 10, Luxtron), placed at the centre of the catalyst bed, which 
was calibrated against a chromel/alumel thermocouple before the catalytic studies commenced.

The product mixture from the reactor outlet was introduced into a quadrupole mass spectrometer (QMS-200D, European Spectrometer Systems) for analysis, which allowed time-resolved monitoring of up to 16 different mass numbers simultaneously. This monitoring system also had two extra channels for temperature/pressure measurements and logging. The relative sensitivity of the mass spectrometer to different gases was obtained by flowing calibrated gas mixtures through the reactor at room temperature in the absence of a catalyst and noting the intensities of the signals. This was done for $\mathrm{CH}_{4} / \mathrm{H}_{2} / \mathrm{Ar}, \mathrm{CO}_{2} / \mathrm{H}_{2} / \mathrm{Ar}$ and $\mathrm{CO} / \mathrm{H}_{2} / \mathrm{Ar}$ mixtures. The product gas was also analyzed with gas chromatography (Perkin-Elmer 8500 Gas Chromatograph) with the samples being collected using a syringe during the reaction. An FID detector was used and the column consisted of 5\% Fluocol phase on a 60/80 Carbopack B support. The compounds analyzed using gas chromatography were methane, acetylene, ethylene and ethane.

All the catalytic reactions were carried out under atmospheric pressure over temperatures ranging from 400 to $1000^{\circ} \mathrm{C}$. The composition of the feed gas mixture was varied by changing the ratio of $\mathrm{CH}_{4}$ to $\mathrm{O}_{2}$, in practice, by varying the flow-rate of the individual gases for different experimental runs, while the flow-rate of the inert gas argon was always kept constant at $30 \mathrm{ml} \mathrm{min}^{-1}$ and the overall gas flow-rate at $60 \mathrm{ml} \mathrm{min}^{-1}$. The weight of catalyst used in all experiments was $0.50 \mathrm{~g}$.

The methane conversion percentage was obtained by calculating from the QMS mass 16 signal, obtained during reaction and after the reaction was stopped by lowering the temperature to $27^{\circ} \mathrm{C}$. The $\mathrm{C}_{2} \mathrm{H}_{6}$ and $\mathrm{C}_{2} \mathrm{H}_{4}$ yields were defined as the percent conversion of the total methane flow to $\mathrm{C}_{2} \mathrm{H}_{6}$ and $\mathrm{C}_{2} \mathrm{H}_{4}$, and were calculated from the area under the gas chromatography traces. The hydrogen yield was present by the number of moles of hydrogen produced as a percentage of the total number of moles of methane flowing over the catalyst.

In the microwave heating system, the microwaves were relayed to the catalyst bed via a co-axial wave guide that was connected to the tuneable cylindrical microwave cavity. The microwave power output and reflected power were measured at different applied powers for all the catalytic runs in order to determine the power absorbed by the catalyst. For an insulated system that is free of microwave leakages, the microwave power absorbed by the catalyst bed can be obtained from the difference between the output power and that reflected.

\section{Results and discussion}

\subsection{Characterization of catalyst}

\subsubsection{Surface area measurement}

The surface area of the alumina supported $10 \%$ $\mathrm{La}_{2} \mathrm{O}_{3} / 20 \% \mathrm{CeO}_{2}$ catalyst was measured before and after the methane oxidative coupling reaction at temperature up to $900{ }^{\circ} \mathrm{C}$. It was found that the surface area of the catalyst was $66.7 \mathrm{~m}^{2} \mathrm{~g}^{-1}$ before reaction, but was reduced to 28.7 and $27.6 \mathrm{~m}^{2} \mathrm{~g}^{-1}$ after the reaction, subject to microwave heating and conventional heating, respectively. This reduction of surface areas is an indication that the structure of the catalyst surface had undergone considerable reconstruction during the reaction.

\subsubsection{X-ray diffraction analysis}

$\mathrm{X}$-ray diffraction patterns of the alumina supported $10 \% \mathrm{La}_{2} \mathrm{O}_{3} / 20 \% \mathrm{CeO}_{2}$ catalyst were obtained before and after each experimental run, using both conventional and microwave heating. An X-ray diffraction pattern was taken with the catalyst sample, which was heated in a methane/argon mixture without oxygen, and the maximum temperatures reached were $1000^{\circ} \mathrm{C}$ with conventional heating and $850^{\circ} \mathrm{C}$ with microwave heating. Another diffraction pattern was taken after reaction in a 7:1 $\mathrm{CH}_{4} / \mathrm{O}_{2}$ gas mixture at a temperature of $1000^{\circ} \mathrm{C}$ for conventional heating and $900{ }^{\circ} \mathrm{C}$ for microwave heating.

In the diffraction pattern of the catalyst before undergoing reaction, $\gamma$-alumina $(2 \theta: 37.5,46.7$ and $\left.67.3^{\circ}\right)$ and cerium oxide ( $2 \theta: 28.5,32.7$ and $\left.47.3^{\circ}\right)$ were the only crystalline phases detected. The absence of lanthanum oxide peaks is indicative that this material has low crystallinity, which could arise either from a very small particle size or the existence of a thin layer of $\mathrm{La}_{2} \mathrm{O}_{3}$ adsorbed on the $\gamma$-alumina particles. This observation was in agreement with the previous studies on the $\mathrm{La}_{2} \mathrm{O}_{3} / \mathrm{CeO}_{2}$ system $[18,19]$. 
With the diffraction pattern of the catalyst that was conventionally heated to $1000^{\circ} \mathrm{C}$ in a $7: 1 \mathrm{CH}_{4} / \mathrm{O}_{2}$ gas mixture, additional sharp peaks were observed which corresponded to lanthanum aluminate $(2 \theta: 23.5,33.6$ and $\left.41.4^{\circ}\right)$ or cerium aluminate $(2 \theta: 23.5,33.4$ and $\left.41.4^{\circ}\right)$. It was difficult to identify which one of these compounds was formed because the XRD peaks for both compounds were very close to one another. However, since the lanthana appeared to be in close contact with the alumina before heating, it is most likely that lanthana aluminate was the aluminate formed. Peaks corresponding to cerium oxide were still evident in the XRD pattern so this material did not seem to have reacted. When the catalyst was microwave heated to $900^{\circ} \mathrm{C}$, the XRD peaks were similar to those obtained after conventional heating except that they were broader and less well defined. This indicated that the catalyst had not been heated to as high a temperature as the conventionally heated sample.

Comparing the diffraction patterns of the catalysts after undergoing reaction in a $\mathrm{CH}_{4} / \mathrm{Ar}$ gas mixture (no oxygen) to $1000^{\circ} \mathrm{C}$ under conventional heating, strong reflections corresponding to the formation of aluminates were also seen but the peaks were relatively broader, an indication that only small crystal- lites had formed. The cerium oxide peaks were also still very much in evidence. When the catalyst was microwave heated to $850^{\circ} \mathrm{C}$, not only did the diffraction pattern show remarkably sharp aluminate peaks, but the size of the remaining cerium oxide peaks was also observed to be very much reduced. It was deduced that nearly all of the cerium oxide had been converted into aluminate. This result indicated that the catalyst had been heated to a much higher temperature than was used with conventional heating and this provided evidence for the formation of localised hot spots.

At high temperatures, the conversion of $\alpha$-alumina from $\gamma$-alumina and the formation of $\mathrm{CeO}_{2} / \mathrm{La}_{2} \mathrm{O}_{3}$ solid solutions have been suggested by other researchers $[19,20]$. However, these changes were not observed significantly in our XRD studies.

\subsection{Reaction of methane with oxygen under microwave and conventional heating conditions}

Experiments were conducted with methane to oxygen ratios of 3:1 under both microwave and conventional heating conditions. The results are shown in Figs. 1-3.

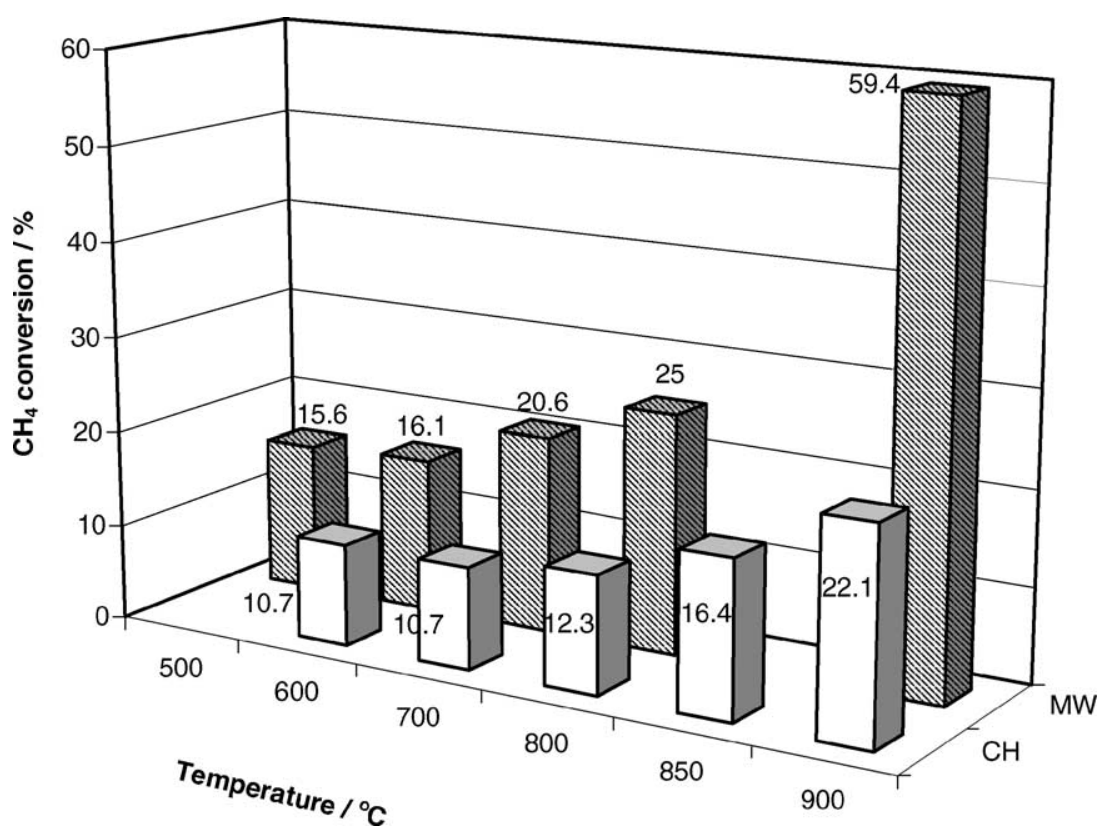

Fig. 1. Conversion of $\mathrm{CH}_{4}$ as a function of temperature using both microwave (MW) and conventional heating $(\mathrm{CH}), \mathrm{CH}_{4} / \mathrm{O}_{2}=3: 1$. 


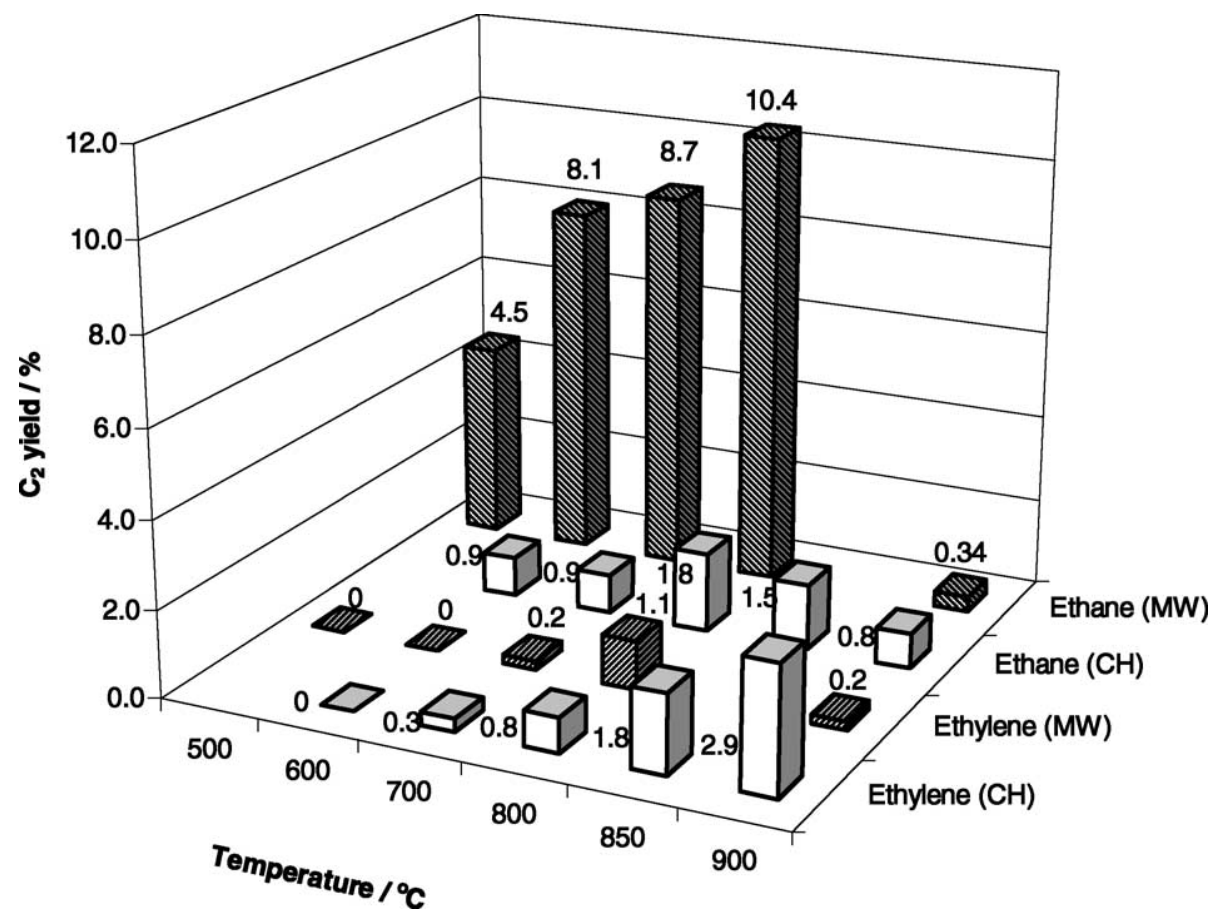

Fig. 2. Percentage conversion of $\mathrm{CH}_{4}$ to $\mathrm{C}_{2}$ hydrocarbons as a function of temperature using both microwave (MW) and conventional heating $(\mathrm{CH}), \mathrm{CH}_{4} / \mathrm{O}_{2}=3: 1$.

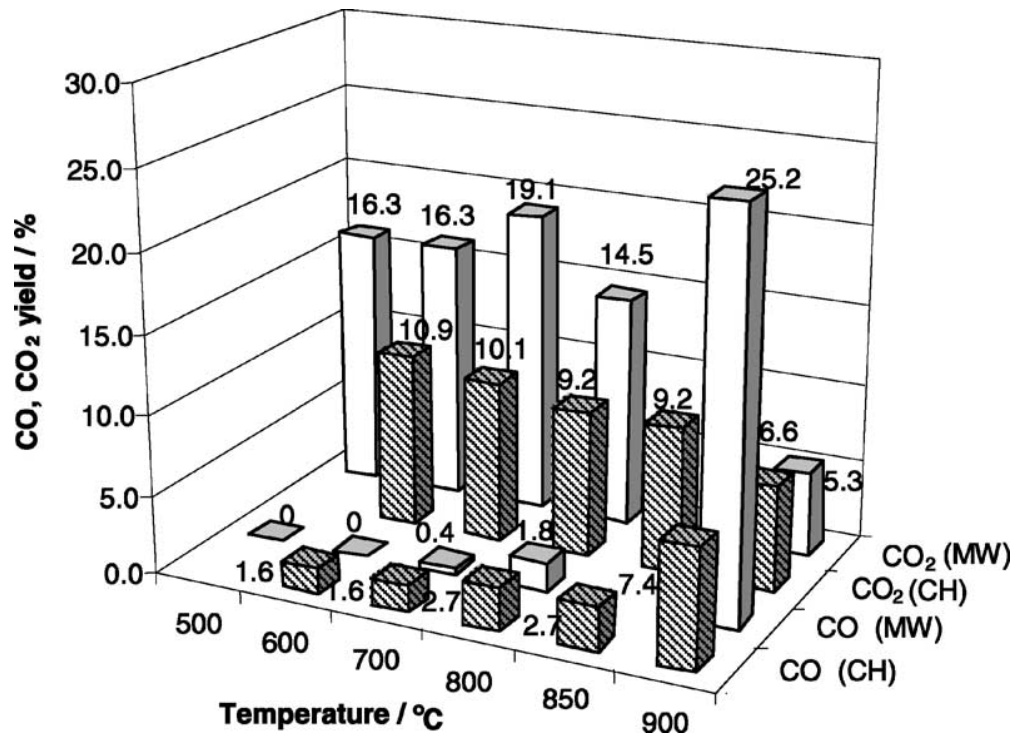

Fig. 3. Percentage conversion of $\mathrm{CH}_{4}$ to $\mathrm{CO}$ and $\mathrm{CO}_{2}$ as a function of temperature using both microwave (MW) and conventional heating $(\mathrm{CH}), \mathrm{CH}_{4} / \mathrm{O}_{2}=3: 1$. 
It can be seen from Fig. 1 that the conversion of methane increased with temperature increasing using both microwave and conventional heating methods, whilst the methane conversion was higher under microwave conditions than that obtained using conventional heating at the same measured temperatures. The results obtained by Bond et al. [12], Roussy et al. [13] and Chen et al. [15] from similar work also showed that reactions under microwave heating conditions at lower temperature than that required with conventional heating. Both Bond and Chen suggested that the explanation for their observations was the formation of "hot spots" that had temperatures very much in excess of the bulk catalyst, stimulating the reaction to occur. In our work the higher conversion of methane under microwave heating conditions compared to that by conventional heating at the same measured temperature was also indicative of the existence of the reaction temperature difference between the two heating methods.

Regardless of whether the catalyst was heated by microwaves or by conventional, the conversion of oxygen was found to be very high especially at high temperatures, i.e. more than $99 \%$ at temperatures $>800^{\circ} \mathrm{C}$. This observation was in keeping with the previous results $[6,7,12]$ and suggested that formation of $\mathrm{C}_{2}$ occurred under oxygen-limited conditions.

Fig. 2 shows the percentage yields of ethane and ethylene as a function of temperature under both conventional and microwave heating conditions. The results illustrated in the figure give a somewhat confusing picture of the effects of microwave heating. It can be seen that ethane was the first hydrocarbon product to be observed, at $500{ }^{\circ} \mathrm{C}$ under microwave conditions and at $600^{\circ} \mathrm{C}$ with conventional heating, and it reached its maximum at $800^{\circ} \mathrm{C}$ in both cases. At $700{ }^{\circ} \mathrm{C}$, ethylene was produced and reached its maximum value at $800^{\circ} \mathrm{C}$ under microwave conditions and $900^{\circ} \mathrm{C}$ with conventional heating. Acetylene formation was not observed under both heating conditions.

It was reported by Chen et al. that acetylene was obtained at temperatures as low as $460^{\circ} \mathrm{C}$ when microwave heating was applied although none was observed with conventional heating. In their work, an infra-red pyrometer was used which allowed the temperature measurements to be taken all along the length of the catalytic bed, enabling temperature uniformity to be monitored, where it was only the surface tem- perature of the catalytic bed that was being measured. Therefore, an accurate measurement of the bulk temperature of the catalytic bed could not be carried out using this method. Thus, the reported temperature of $460^{\circ} \mathrm{C}$ where acetylene production was first observed might not be representative of the temperature in the middle of the catalyst bed. It should be noticed, however, that these workers were using different catalysts (nickel on alumina) and the existence of hot spots on these catalysts cannot be ruled out. It will be shown in a later section that the catalyst used in this work could show large hot spot effects when heated with a flow of methane and in the absence of oxygen.

Fig. 3 shows the percentage yields of $\mathrm{CO}$ and $\mathrm{CO}_{2}$ as a function of temperature under both conventional and microwave heating conditions. It was observed, at low temperatures, the main products were $\mathrm{CO}_{2}$ and $\mathrm{H}_{2} \mathrm{O}$ but as the temperature raised, the percentage of $\mathrm{CO}$ and $\mathrm{H}_{2}$ increased to become the predominant reaction at $900^{\circ} \mathrm{C}$ and above. The result obtained was in keeping with other researches' results that the formation of $\mathrm{CO}_{2}$ at low temperature and $\mathrm{CO}$ at higher temperature was always observed in methane oxidation [6-9]. This was due to the thermodynamic equilibrium between $\mathrm{CO}$ and $\mathrm{CO}_{2}$. In general, the product analysis results showed that most of the methane reacted to give $\mathrm{CO}_{2}, \mathrm{CO}, \mathrm{H}_{2} \mathrm{O}$ and $\mathrm{H}_{2}$, and only a small percentage resulted in $\mathrm{C}_{2}$ hydrocarbon formation. The two main reactions occurring were:

$\mathrm{CH}_{4}+2 \mathrm{O}_{2} \rightarrow \mathrm{CO}_{2}+2 \mathrm{H}_{2} \mathrm{O}$

and

$\mathrm{CH}_{4}+\frac{1}{2} \mathrm{O}_{2} \rightarrow \mathrm{CO}+2 \mathrm{H}_{2}$.

A secondary reaction of the reforming of methane with carbon dioxide produced from reaction (1) could also occur:

$\mathrm{CH}_{4}+\mathrm{CO}_{2} \rightarrow 2 \mathrm{CO}+2 \mathrm{H}_{2}$.

This could significantly affect the product distribution of the overall process. With a 3:1 methane/oxygen ratio, microwave heating gave a higher percentage of reacted methane than conventional heating at the same nominal temperature. However, this was observed to be almost entirely due to a greater production of $\mathrm{CO}$ and $\mathrm{CO}_{2}$.

It was also observed that under both microwave and conventional heating conditions at temperatures up to 


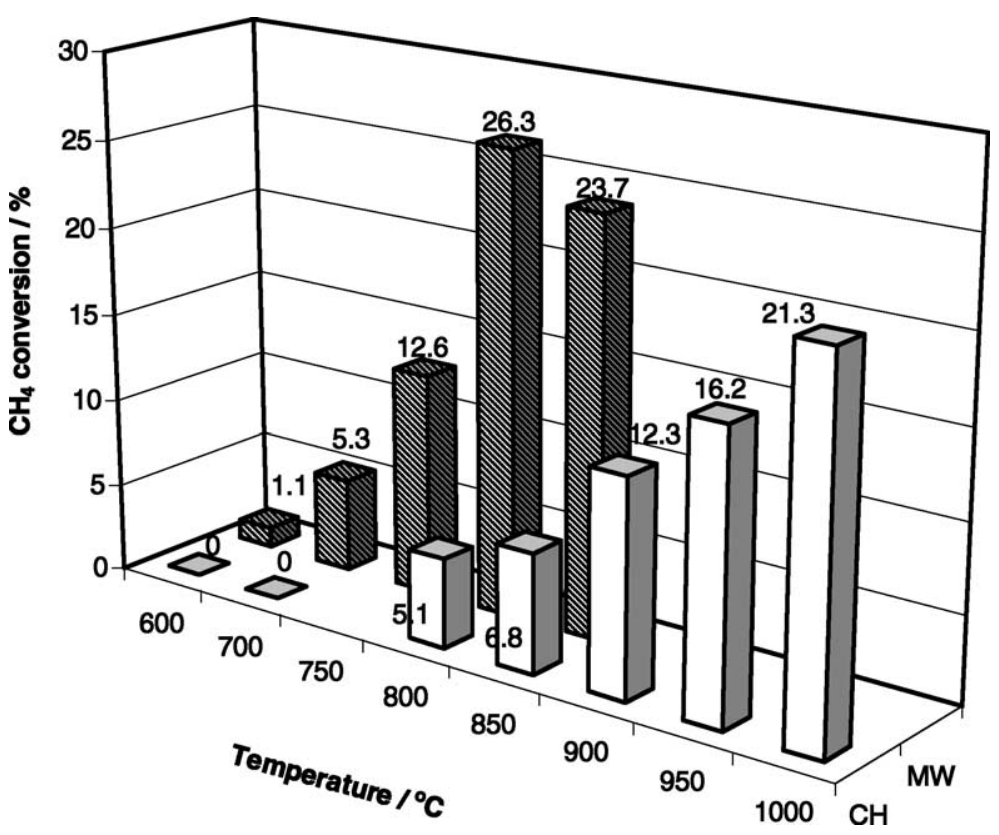

Fig. 4. Conversion of $\mathrm{CH}_{4}$ as a function of temperature in absence of $\mathrm{O}_{2}$ using both microwave (MW) and conventional heating (CH).

$900^{\circ} \mathrm{C}$, the catalysts appeared to be quite stable and it was possible to obtain reproducible results, when the temperature was raised and lowered over a period of about $2 \mathrm{~h}$, after an initial period of about $0.5 \mathrm{~h}$.

\subsection{Reaction of methane without oxygen under microwave and conventional heating conditions}

Figs. 4 and 5 show the methane conversion and $\mathrm{C}_{2}$ yield versus temperature under both microwave and conventional heating conditions in absence of oxygen. It can be seen that microwave heating had a dramatic effect on the production of $\mathrm{C}_{2}$ hydrocarbons in the absence of oxygen. Ethane production was seen at temperatures as low as $600^{\circ} \mathrm{C}$, some $250{ }^{\circ} \mathrm{C}$ below the temperature at which ethane was first detected under conventional heating. As the temperature was raised further, the ethylene signal became dominant with a $14.7 \%$ conversion at temperatures between 850 and $900^{\circ} \mathrm{C}$. In contrast to the run using conventional heating, ethane only appeared when the temperature of the reaction exceeded $850^{\circ} \mathrm{C}$, followed by ethylene production between 900 and $1000^{\circ} \mathrm{C}$.

The results observed are in agreement with the results obtained by Marun et al. [21], Suib and Zerger
[22] and Suib [23]. In the oligomerization of methane to higher hydrocarbons carried out by Marun et al. using microwave heating, their results showed arc formation and discharges produced by the catalyst. Ethane was observed to be the major product produced at the beginning of the reaction. However, when arc formation was noticeable, significant selectivity to ethylene and acetylene was obtained. Acetylene production was then seen to increase at high microwave power when arcing was present. This result is in accord with earlier data for the oligomerization of methane via microwave plasmas [24]. The catalyst was also thought to have undergone a change in dielectric properties upon heating in microwave field, and this may have drastically altered their ability to interact with the applied field.

Similar results were also obtained by Suib and co-workers where the arcing process during microwave plasma catalysis of methane was observed to be very selective towards acetylene production. This observation was attributed to the existence of a unique mechanism for the generation of non-thermodynamic equilibria in discharges during catalytic reactions, leading to significant changes in activity and selectivity of the catalyst. Therefore, due to the significant similarities observed with the results obtained in our 


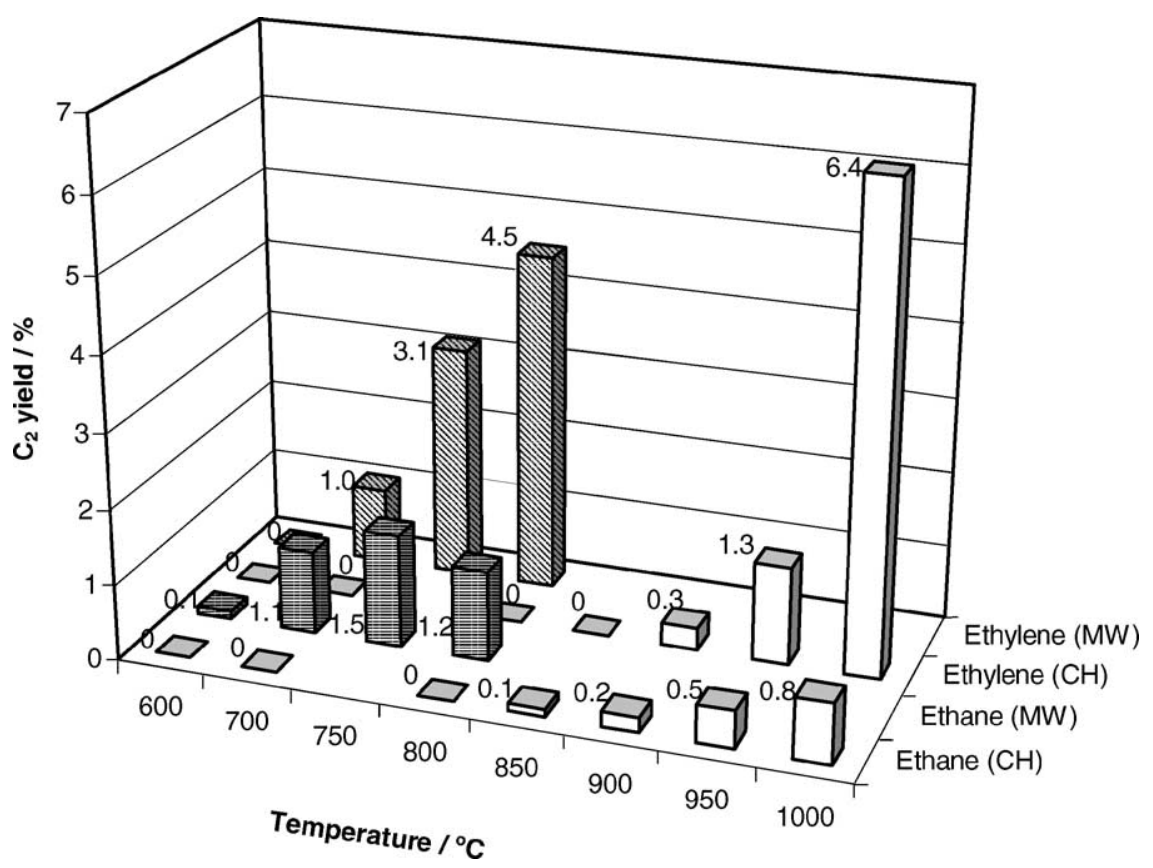

Fig. 5. Percentage conversion of $\mathrm{CH}_{4}$ to $\mathrm{C}_{2}$ hydrocarbons as a function of temperature in absence of $\mathrm{O}_{2}$ using both microwave (MW) and conventional heating $(\mathrm{CH})$.

work and the results obtained from the work reported by Marun et al. and Suib and co-workers, it is plausible to conclude that, in the absence of oxygen, microwave plasma catalysis of methane was responsible for the increase in ethylene and acetylene selectivities when the temperature reached $850^{\circ} \mathrm{C}$. On the other hand, the presence of oxygen in the gas mixture is likely to mop up any free radicals present in the gas phase and therefore, to inhibit plasma discharge and arcing. This would explain why anomalously high temperature and acetylene production were not observed when methane/oxygen mixtures were used.

The methane pyrolysis results are most likely indicative of hot spot formation, that is, the existence of localised parts of the catalyst that are at a much higher temperatures than the surrounding material. When the hot spot is formed the heat generated by microwave irradiation must be dissipated and it is inevitable that significant temperature gradients will exist between the centre and the periphery of the catalyst. However, the analysis [25] on the temperature difference between the catalyst and the gas revealed that this temperature difference was negligible $\left(1.1 \times 10^{-10} \mathrm{~K}\right)$ mainly due to the rapid heat transfer via the gas phase in a platinum-air-alumina system under microwave heating conditions. Thus, the most likely explanation for the occurrence of these so-called "hot spots" is arc formation leading to discharges between catalyst particles. In addition, if the dielectric loss factor of the component absorbing the microwaves has a high enough temperature coefficient, there is the possibility that inhomogeneous in the electromagnetic field will lead to a localised thermal runaway.

\subsection{Reaction of methane with oxygen in absence of catalyst}

It is important to determine whether a homogeneous or heterogeneous reaction was occurring for understanding the effect of microwave heating on this reaction.

Experimental runs were carried out without the catalyst and the results were compared with the runs carried out in the presence of a catalyst at a methane/ oxygen ratio of 7:1. The results are present in Figs. 6 and 7. Comparison of the two runs showed that ethane 


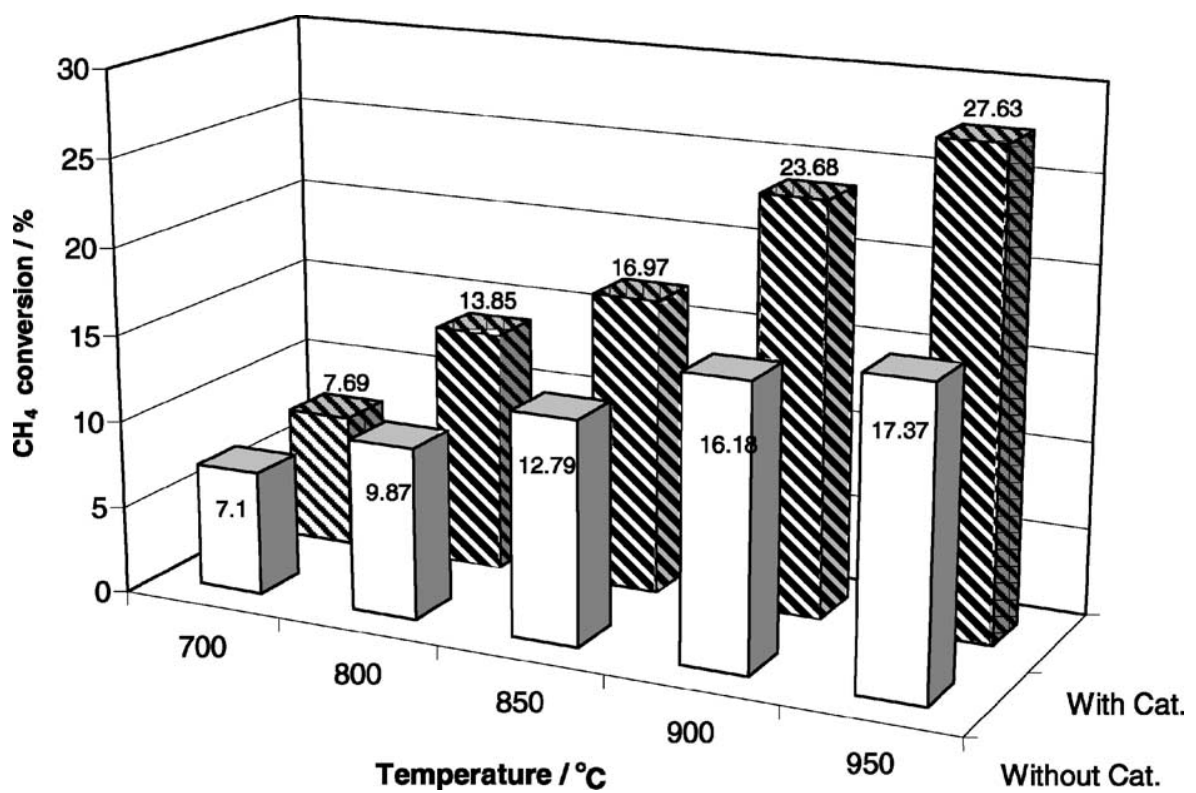

Fig. 6. Conversion of $\mathrm{CH}_{4}$ as a function of temperature in both present and absence of the catalyst, $\mathrm{CH}_{4} / \mathrm{O}_{2}=7: 1$.

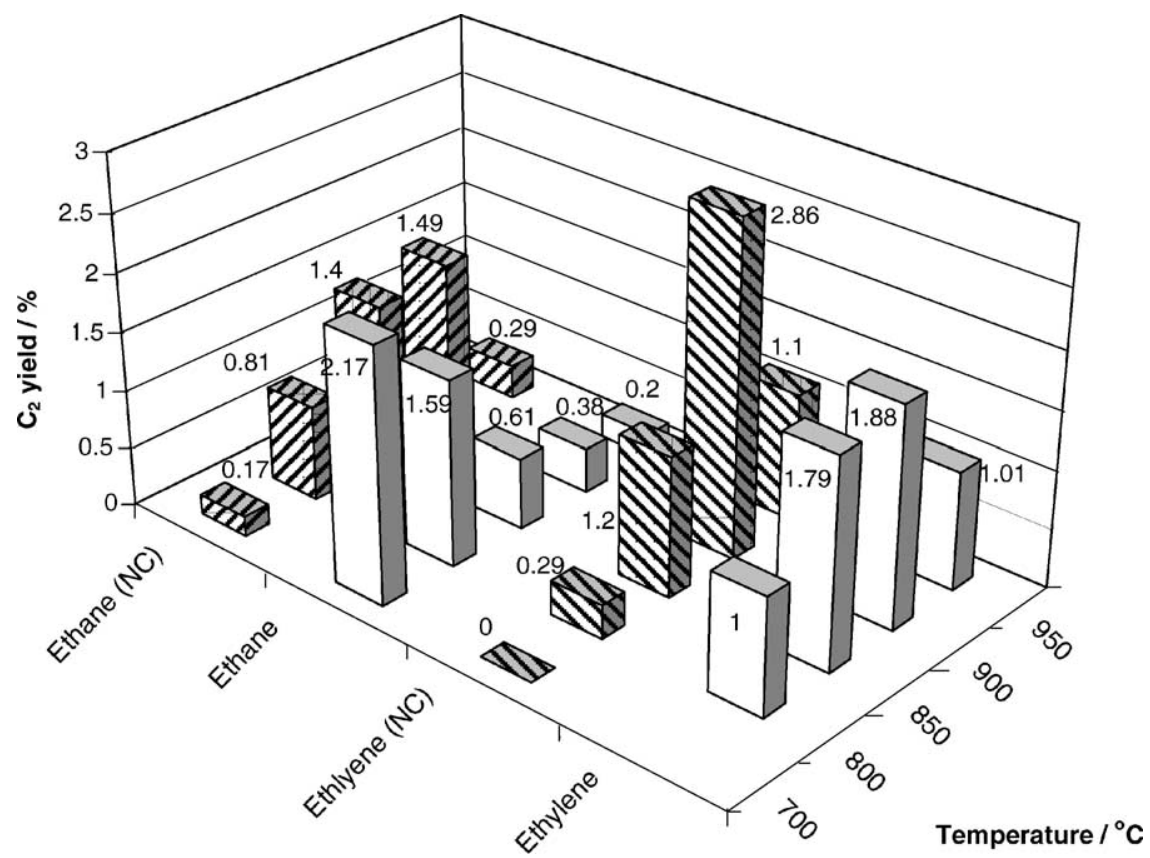

Fig. 7. Conversion of $\mathrm{CH}_{4}$ to $\mathrm{C}_{2}$ hydrocarbons in absence of $\mathrm{O}_{2}$ as a function of temperature in both present and absence of the catalyst (NC: no catalyst). 
was produced at $600^{\circ} \mathrm{C}$ with the catalyst present and not until $700{ }^{\circ} \mathrm{C}$ when the catalyst was absent. However, ethylene was observed as a product over an identical temperature range whether the catalysts was present or absent, indicating that this particular reaction was occurring in the gas phase.

In the presence of the catalyst, the maximum production of $\mathrm{C}_{2}$ hydrocarbons occurred at $800^{\circ} \mathrm{C}$, where $14 \%$ of the methane had reacted. In the absence of the catalyst, the best results were obtained at $900{ }^{\circ} \mathrm{C}$ where $16 \%$ of the methane had reacted. Overall, the catalyst did not contribute significantly in improving the yield of the reaction products although it did reduce the temperature at which the reaction could effectively be operated by about $100^{\circ} \mathrm{C}$. Comparison of the two reactions studied showed a slight increase in the percentage of methane conversion when a catalyst was used in the reaction. However, most of the reacted methane was involved in reactions producing $\mathrm{CO}, \mathrm{CO}_{2}$ and hydrogen. This result was observed for both runs, with the runs using a catalyst giving a higher percentage yield of $\mathrm{CO}, \mathrm{CO}_{2}$ and hydrogen.

When oxidative coupling was carried out without a catalyst, the ethane and ethylene products observed were thought to have formed via a gas-phase reaction. Similar work carried out by Lane and Wolf [26] produced results that showed conclusively that oxidative coupling occurred in the gas phase in the absence of a catalyst. Their results also showed that the reaction was not catalysed by the reactor wall materials. In experiments conducted to test the activity of the reactor wall materials and the catalyst support (alumina), it was found that quartz and alumina reactors did not have active sites for the reaction. These results also included quartz wool and quartz chips, materials frequently used for the packing of the reactor. In contrast, they observed that stainless steel reactors significantly affected the reaction results, indicating that the metal walls can act as a catalyst. Acetylene was not observed in their reaction products.

It was also observed by Lane et al. that no reaction occurred for temperatures less than $850^{\circ} \mathrm{C}$ when methane was fed without oxygen, and this is consistent with studies on methane pyrolysis that have indicated that methane is converted at temperatures greater than $1000^{\circ} \mathrm{C}[27,28]$. However, when oxygen was present, methane conversion was observed to occur at much lower temperatures, $600-850{ }^{\circ} \mathrm{C}$. This observation indicated that some type of gas-phase oxygen species was required to activate methane at these lower temperatures.

In general, the selectivity for the formation of $\mathrm{C}_{2}$ hydrocarbons increases with the increase in $\mathrm{CH}_{4} / \mathrm{O}_{2}$ ratios. However, it was found by comparing the data shown in Figs. 2 and 7 that the total $\mathrm{C}_{2}$ yield at $\mathrm{CH}_{4} / \mathrm{O}_{2}=3: 1$ was slightly higher than that at $\mathrm{CH}_{4} / \mathrm{O}_{2}=7: 1$, e.g. $\mathrm{C}_{2}$ yield $3.3 \%$ at $\mathrm{CH}_{4} / \mathrm{O}_{2}=3: 1$ and $2.4 \%$ at $\mathrm{CH}_{4} / \mathrm{O}_{2}=7: 1$ at a temperature of $850^{\circ} \mathrm{C}$. The cause for this difference is still not clear.

\subsection{Reaction of methane in absence of oxygen without catalyst}

In order to propose a reasonable explanation for the effect of microwave heating on this reaction, it is also important to examine the reaction under pyrolysis conditions in absence of oxygen. Experimental runs without a catalyst were carried out and compared to those with a catalyst under conventional heating conditions. The results are depicted in Figs. 8 and 9. It was found that ethane production was not observed until the temperature exceeded $850^{\circ} \mathrm{C}$, while ethylene was formed at a slightly higher temperature $\left(900^{\circ} \mathrm{C}\right)$. In both cases, the production of ethylene greatly exceeded that of ethane at a temperature of $950{ }^{\circ} \mathrm{C}$. The experiment without a catalyst also gave significant amounts of acetylene (2.4\%), which was not observed when the catalyst was present during the reaction.

From the figures it is apparent that the reaction occurring could essentially be a homogeneous gas-phase reaction with the catalyst playing no part in the initial steps of the reaction. Similar to the gas-phase mechanism of the oxidative coupling reaction without a catalyst, the methyl radicals must be formed by the dissociation of methane either through collision with the reactor walls or with another methane molecule. There is another possible interpretation that the quartz wool present, whether or not a catalyst was used, could be acting as an effective catalyst for the formation of the methyl radicals. However, Chen et al. [29] found no difference in the rate of methane pysolysis when their reaction vessel was filled with quartz tubes to increase the surface area of reaction by a factor of 10 . This observation is also supported by the study of Lane et al. on the effect of the reactor material affecting the cat- 


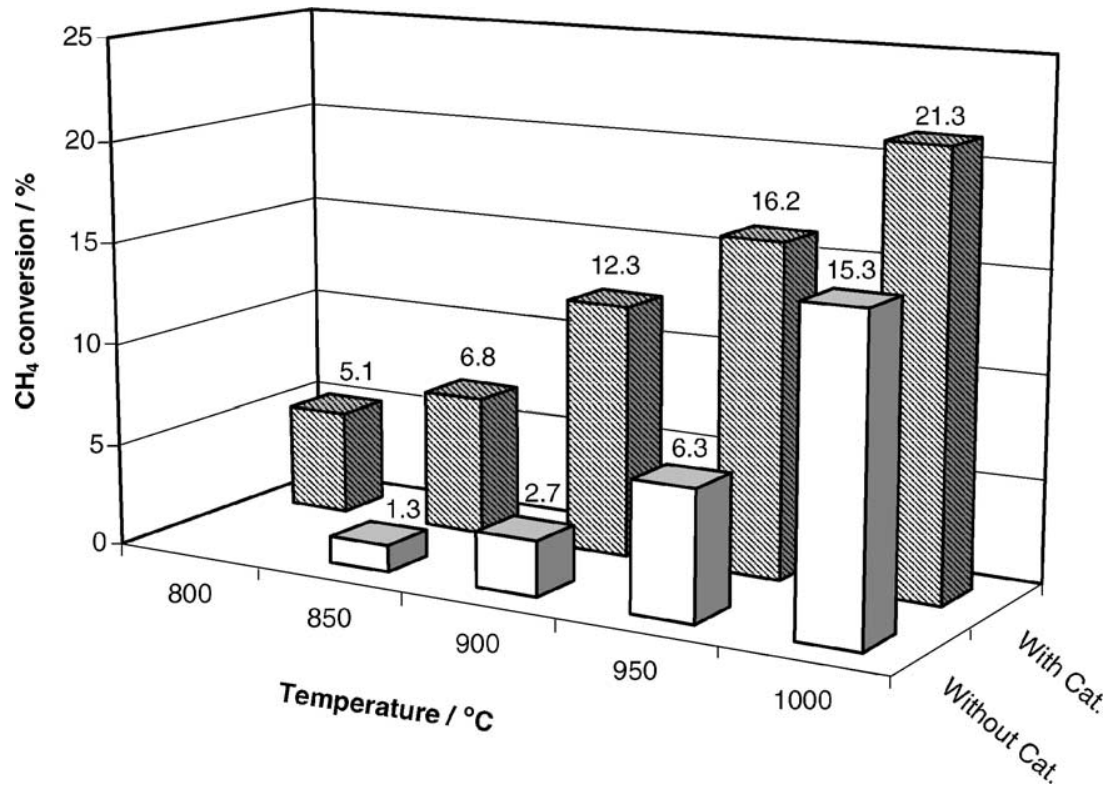

Fig. 8. Conversion of $\mathrm{CH}_{4}$ in absence of $\mathrm{O}_{2}$ as a function of temperature in both present and absence of the catalyst.

alytic results of oxidative coupling without a catalyst. Based on this evidence, it is very unlikely that the surface of the quartz wool plays a significant part in the reaction.
On the other hand, Fig. 8 shows that a higher percentage of methane conversion was obtained when the reaction was carried out with a catalyst. It can be seen from Fig. 9 that the production of hydrogen more than

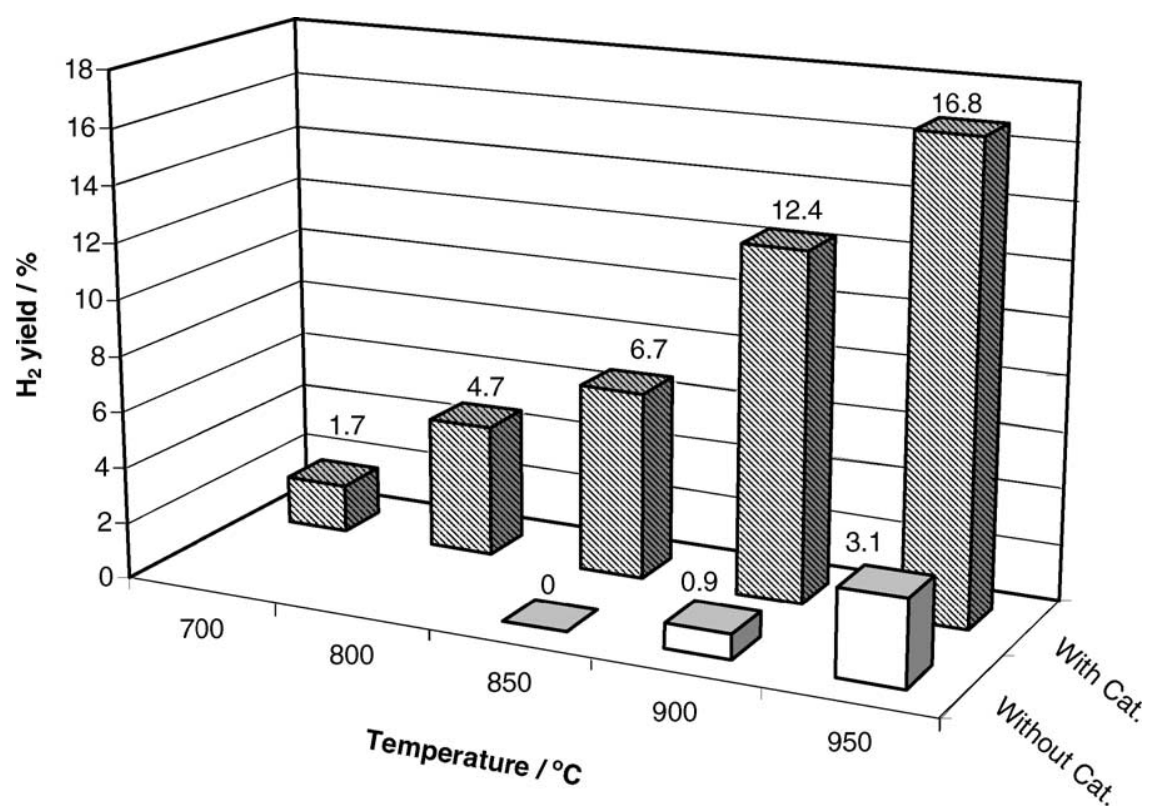

Fig. 9. Conversion of $\mathrm{CH}_{4}$ to $\mathrm{H}_{2}$ in absence of $\mathrm{O}_{2}$ as a function of temperature in both present and absence of the catalyst. 
doubled when a catalyst was present. Thus, the catalyst appeared to catalyse the dehydrogenation of methane to form carbon and therefore, has an undesirable effect on the reaction. This result was in keeping with the observation by Otsuka et al. [30] for the partial oxidation of methane using the redox of cerium oxide. In the system with catalysts in absence of gas-phase oxygen supply, cerium oxide could act as oxygen storage and the redox cycle of cerium oxide enabled the direct conversion of methane into synthesis gas and the conversion of $\mathrm{CO}_{2}$ to $\mathrm{CO}$. The absence of acetylene when the catalyst was present is likely due to the strong adsorption of this compound on the catalyst surface, followed by dehydrogenation to carbon.

These results can be compared with those observed by Back and Back [31] in a static system at a temperature of $765^{\circ} \mathrm{C}$. The course of their reaction was found to develop with time in three stages, all of which occurred before the total conversion of methane had reached $2 \%$. In the primary stage, ethane and hydrogen were the only products observed; in the second stage, the concentration of ethane was seen to reach a plateau whilst the ethylene concentration was still increasing rapidly. Acetylene and propylene were then observed in the third stage. Comparing the results shown in Figs. 8 and 9, it can be seen that the results of the study here appear to correlate with the second stage of Back's mechanism rather well, except for the observation of acetylene at this stage instead of the third stage. In view of this, the results obtained with the catalyst present appear to be more consistent with a gas-phase reaction rather than a surface-catalyst reaction, with the catalyst playing no part in the initial stages of the reaction. The much lower temperature measured when microwave radiation is used must arise from temperature gradients within the catalyst. These temperature gradients will cause localised heating of the gaseous reactants because of the high rate of heat transfer between the internal surface of the catalyst and the gas phase, as investigated in our earlier work [32].

\subsection{Microwave power as a function of the temperature of catalyst bed}

Fig. 10 shows the output and reflected microwave power as a function of temperature for the supported catalyst. The calculated absorbed power at different temperatures is also plotted in the figure. It can be seen

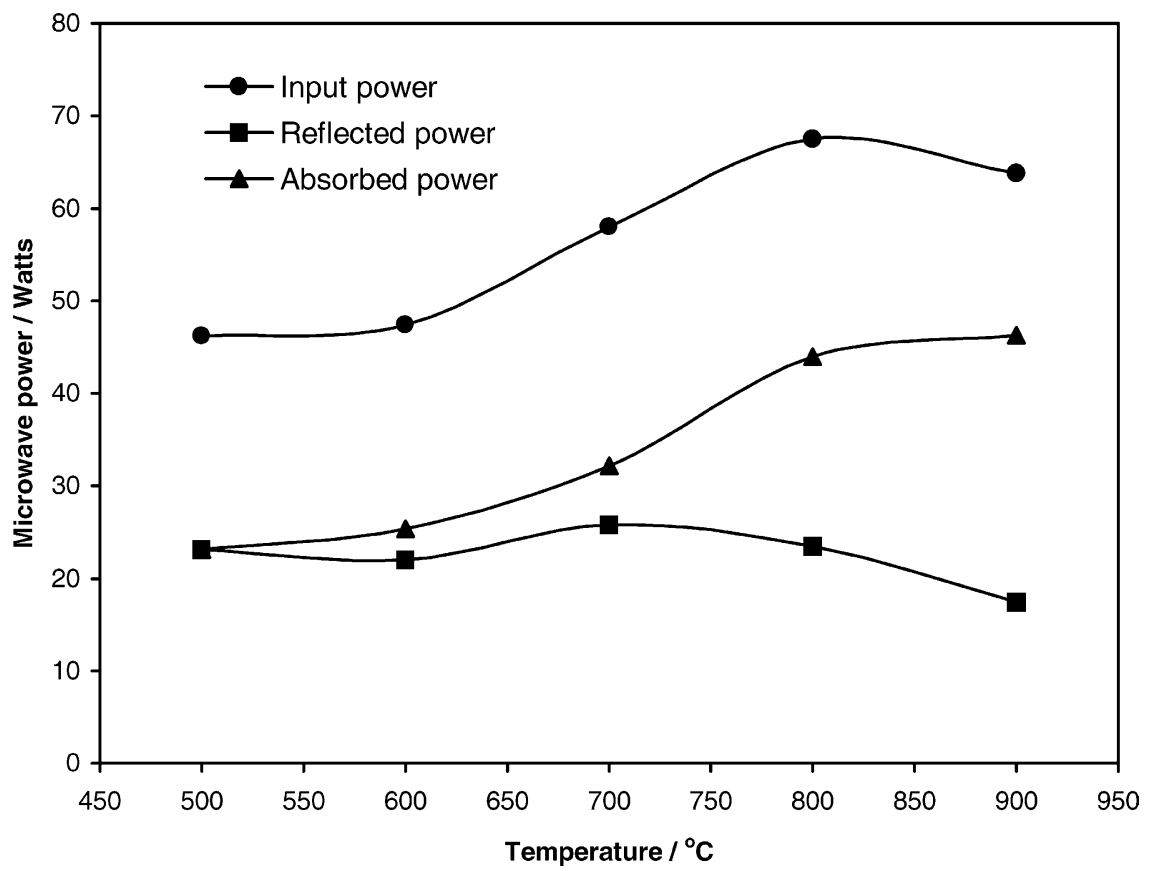

Fig. 10. Microwave power as a function of temperature for the supported catalyst. 


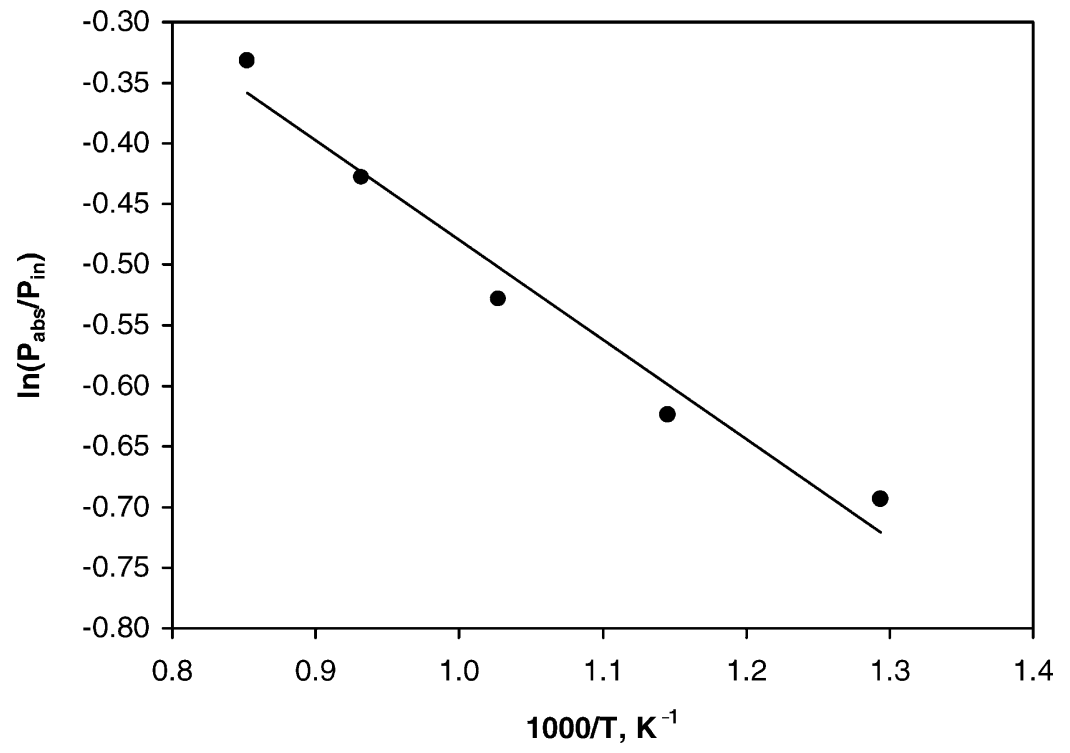

Fig. 11. Plot of $\ln \left(P_{\mathrm{abs}} / P_{\text {in }}\right)$ vs. $1000 / T$ for the supported catalyst.

that the input power needed to be increased to raise the catalyst temperature up to $800^{\circ} \mathrm{C}$. However, a lower input power was needed to reach $900^{\circ} \mathrm{C}$, while the reflected power decreased. This indicated an increase in microwave heating efficiency at higher temperatures, and may be attributed to the increase in the dielectric loss of the catalyst with increasing temperature [32].

With microwave heating the fraction of microwave power absorbed over input power was observed to increase approximately exponentially with temperature throughout the temperature range used. Fig. 11 shows an Arrhenius plot of the data, from which an activation energy of $6.8 \mathrm{~kJ} \mathrm{~mol}^{-1}$ was calculated.

According to Kenkre et al. [33], the ratio $P_{\text {abs }} / P_{\text {in }}$ should be roughly proportional to $\varepsilon_{\mathrm{eff}}^{\prime \prime}$, and the variation of $\varepsilon_{\text {eff }}^{\prime \prime}$ with temperature is presented as:

$\varepsilon_{\mathrm{eff}}^{\prime \prime}=k_{\mathrm{A}}+k_{\mathrm{M}} \exp \left(-\frac{E_{\mathrm{a}}}{R T}\right)$

where the constants $k_{\mathrm{A}}$ and $k_{\mathrm{M}}$ are measures of the contribution made by localised and mobile microwave absorbers, respectively. It can be seen that all the experimental points shown in Fig. 11 lie on a straight line and the data fit well with Kenkre's equation. This result confirms, in further, the strong temperature dependence of the dielectric loss of the catalyst.

\section{Conclusions}

The conversion of methane into $\mathrm{C}_{2}$ hydrocarbons, with and without oxygen, has been investigated using both microwave and conventional heating.

For the oxidative coupling reaction occurring in the presence of oxygen, there was no significant difference between the temperatures at which products were first observed using the two heating methods, nor was there any significant difference in selectivities. Thus, microwave heating showed no significant effects that could make it an advantageous method of heating. When methane was converted into $\mathrm{C}_{2}$ hydrocarbons in the absence of oxygen, microwave heating was found to have a dramatic effect on the reaction, with products appearing at measured temperatures about $250^{\circ} \mathrm{C}$ lower than those observed with conventional heating. This effect was believed to be due to $\mathrm{CH}_{4}$ plasma formation and arcing, leading to the establishment of a high temperature gradient within the catalyst, with the result that the temperature probe did not record the true temperature at the centre of the catalyst bed. It has been shown that the reaction in the absence of oxygen occurred primarily in the gas phase and it was the localised heating of the methane that was responsible for the increased reaction rate. 
The results obtained showed that the magnitude of the temperature gradient set up within the catalyst bed can vary enormously depending on the dielectric loss characteristics of the catalyst. Heating the catalyst in the absence of oxygen seemed to alter the dielectric loss characteristics and increase the temperature difference between the centre and the periphery of the catalyst.

\section{References}

[1] Y.H. Hu, E. Ruckenstein, Catal. Rev. 44 (2002) 423.

[2] G. Veser, J. Frauhammer, U. Friedle, Catal. Today 61 (2000) 55.

[3] V.R. Choudhary, S.D. Sansare, A.S. Mamman, Appl. Catal. A-Gen. 90 (1992) L1.

[4] M.K. Dry, Catal. Today 71 (2002) 227.

[5] G.E. Keller, M.M. Bhasin, J. Catal. 73 (1982) 9.

[6] V.R. Choudhary, S.A.R. Mulla, B.S. Uphade, Ind. Eng. Chem. Res. 37 (1998) 2142.

[7] V.R. Choudhary, S.A.R. Mulla, V.H. Rane, J. Chem. Technol. Biotechnol. 71 (1998) 167.

[8] G. Gayko, D. Wolf, E.V. Kondratenko, M. Baerns, J. Catal. 174 (1998) 441.

[9] Y. Wang, Y. Takahashi, Y. Ohtsuka, Appl. Catal. A: Gen. 172 (1998) L203.

[10] J.K.S. Wan, J. Kriz, US Patent 4,545,879 (1985).

[11] J.K.S. Wan, US Patent 4,574,038 (1986).

[12] G. Bond, R.B. Moyes, D.A. Whan, Catal. Today 17 (1993) 427.

[13] G. Roussy, E. Marchal, J.M. Thiebaut, A. Kiennemann, G. Maire, Fuel Process. Technol. 50 (1997) 261.

[14] J.K.S. Wan, M.Y. Tse, H. Husby, M.C. Depew, J. Microwave Power Electromagn. Energy 25 (1990) 32.
[15] C. Chen, P. Hong, S. Dai, J. Kan, J. Chem. Soc., Faraday Trans. 92 (1995) 1179

[16] X.L. Zhang, D.O. Hayward, D.M.P. Mingos, Chem. Commun. (1999) 975.

[17] X.L. Zhang, C. Lee, D.O. Hayward, D.M.P. Mingos, Appl. Catal. B: Environ. 33 (2001) 137.

[18] G. Colon, J.A. Navio, R. Monaci, I. Ferino, Phys. Chem. Chem. Phys. 2 (2000) 4453.

[19] G. Groppi, C. Cristiani, L. Lietti, C. Ramella, M. Valentini, P. Forzatti, Catal. Today 50 (1999) 399.

[20] M. O'Connell, M.A. Morris, Catal. Today 59 (2000) 387.

[21] C. Marun, L.D. Conde, S.L. Suib, J. Phys. Chem. A 103 (1999) 4332.

[22] S.L. Suib, R.P. Zerger, J. Catal. 139 (1993) 383.

[23] S.L. Suib, CATTECH 3 (1998) 76.

[24] C. Marun, S.L. Suib, M. Dery, J.B. Harrison, M.J. Kablaoui, J. Phys. Chem. 100 (1996) 17866.

[25] W.L. Perry, D.W. Cooke, J.D. Katz, A.K. Datye, Catal. Lett. 47 (1997) 1.

[26] G.S. Lane, E.E. Wolf, J. Catal. 113 (1988) 144.

[27] C. Gueret, M. Daroux, F. Billaud, Chem. Eng. Sci. 52 (1997) 815.

[28] A. Chauvel, G. Lebfevre, L. Castex, Procedes de Petrochemie-Caracteristiques Techniques et Economiques 1 (1983) 343.

[29] C.J. Chen, M.H. Back, R.A. Back, Can. J. Chem. 53 (1975) 3580 .

[30] K. Otsuka, T. Ushiyama, I. Yamanaka, Chem. Lett. (1993) 1517.

[31] M.H. Back, R.A. Back, Pyrolysis Theory and Industrial Practice, Academic Press, New York, 1983.

[32] X.L. Zhang, D.O. Hayward, D.M.P. Mingos, Ind. Eng. Chem. Res. 40 (2001) 2810.

[33] V.M. Kenkre, L. Skala, M.W. Weiser, J.D. Katz, J. Mater. Sci. 26 (1991) 2483. 